\title{
Host-dependent control of early regulatory and effector T-cell differentiation underlies the genetic susceptibility of RAG2-deficient mouse strains to transfer colitis
}

\author{
V Valatas ${ }^{1,6}, \mathrm{~J} \mathrm{He}^{2,6}$, A Rivollier ${ }^{3}, \mathrm{G} \mathrm{Kolios}^{4}, \mathrm{~K}_{\text {Kitamura }}^{5}$ and BL Kelsall ${ }^{2}$
}

De novo differentiation of $\mathrm{CD}_{4}{ }^{+} \mathrm{Foxp}^{+}{ }^{+}$regulatory Tcells (induced (i) Tregs) occurs preferentially in the gut-associated lymphoid tissues (GALT). We addressed the contribution of background genetic factors in affecting the balance of iTreg, Thelper type 1 (Th1), and Th17 cell differentiation in GALT in vivo following the transfer of naive CD4 ${ }^{+}$CD45RB ${ }^{\text {high }}$ Tcells to strains of RAG2-deficient mice with differential susceptibility to inflammatory colitis. iTregs represented up to $5 \%$ of $\mathrm{CD}^{+}{ }^{+}$T cells in mesenteric lymph nodes of less-susceptible C57BL/6 RAG2 ${ }^{-1-}$ mice compared with $<1 \%$ in highly susceptible C57BL/10 RAG2 ${ }^{-1-}$ mice 2 weeks following T-cell transfer before the onset of colitis. Early Treg induction was correlated inversely with effector cell expansion and the severity of colitis development, was controlled primarily by host and not T-cell-dependent factors, and was strongly associated with interleukin-12 (IL-12)/23 production by host $\mathrm{CD}_{11 \mathrm{C}}{ }^{+} \mathrm{CD}_{103}{ }^{+}$dendritic cells. These data highlight the importance of genetic factors regulating IL-12/23 production in controlling the balance between iTreg differentiation and effector-pathogenic $\mathrm{CD} 4{ }^{+} \mathrm{T}$-cell expansion in lymphopenic mice and indicate a direct role for iTregs in the regulation of colonic inflammation in vivo.

\section{INTRODUCTION}

Although the pathogenesis of human Crohn's disease (CD) is still poorly understood, it is now widely believed that the intestinal inflammation of this devastating condition represents a dysregulated immune response to commensal bacterial antigens. ${ }^{1}$ Furthermore, data from mouse models and human disease support a primary role for unrestrained $\mathrm{CD} 4^{+} \mathrm{T}$-cell responses in driving this inflammation. This is likely due to some combination of interferon- $\gamma$ (IFN- $\gamma$ )-producing T helper type 1 (Th1) cells and pathogenic Th17 cells induced by the production of interleukin-12 (IL-12) and/or IL-23 by dendritic cells (DCs) and macrophages, ${ }^{2-6}$ although the colitogenic potential of Th17 cells has recently been challenged by experimental data in mice showing a protective role for IL17A in colitis development. ${ }^{7}$ Experimental colitis using p19 knock out mice has shown a critical role for IL-23 in driving these pathogenic intestinal immune responses ${ }^{6,8-10}$ and restraining regulatory $\mathrm{T}$-cell (Treg) differentiation in mice. ${ }^{11}$

To maintain intestinal homeostasis, such pathogenic immune responses in the gut are constantly restrained by a number of factors, including $\mathrm{CD} 4{ }^{+} \mathrm{CD} 25^{+}$Foxp $^{+}$Tregs. ${ }^{1}$ Co-transfer or subsequent transfer of Tregs is able to prevent or cure experimental colitis following transfer of $\mathrm{CD} 4^{+}$ $\mathrm{CD} 45 \mathrm{RB}^{\text {high }}$ naive $\mathrm{T}$ cells to RAG2 ${ }^{-1-}$ mice, respectively. ${ }^{12,13}$ Aside from thymically derived "natural" Tregs (nTregs), $\mathrm{CD} 4{ }^{+} \mathrm{Foxp}^{+} \mathrm{T}$ cells can also be induced outside the thymus (iTregs), ${ }^{14}$ particularly in the gut-associated lymphoid tissues (GALT) following interactions with $\mathrm{CD} 103^{+}$DCs in a transforming growth factor- $\beta$ (TGF- $\beta$ )- and retinoic aciddependent manner. ${ }^{15-17}$ iTregs can have suppressive functions similar to nTregs in vitro ${ }^{15,16,18,19}$ and may represent a high proportion of the total $\mathrm{CD} 4{ }^{+} \mathrm{Foxp}^{+}{ }^{+}$Tregs in peripheral

\footnotetext{
${ }^{1}$ Department of Gastroenterology, Heraklion University Hospital, Heraklion, Crete, Greece. ${ }^{2}$ Mucosal Immunobiology Section, Laboratory of Molecular Immunology NIAID National Institute of Health, Bethesda, Maryland, USA. ${ }^{3}$ Immunology Section, Department of Experimental Medical Science, Lund University, Lund, Sweden. ${ }^{4}$ Laboratory of Pharmacology, School of Medicine, Democritus University of Thrace Dragana, Alexandroupolis, Greece and ${ }^{5}$ Department of Gastroenterology, Kanazawa University Hospital, Kanazawa, Japan. Correspondence: B Kelsall (kelsall@nih.gov)

${ }^{6}$ These authors contributed equally to this work.
} 
compartments. ${ }^{20}$ However, the precise role for iTregs in regulating intestinal homeostasis is not yet clear, as recent studies have come to contradictory conclusions regarding their importance in experimental colitis models. ${ }^{11,21}$

Inbred mouse strains that differ in their susceptibility to autoimmune diseases offer an important tool for understanding complex disorders like inflammatory bowel disease, because it allows the study of disease evolution in the context of minimal genetic heterogeneity and controlled environmental influences. The C57BL/6 (B6) and C57BL/10 (B10) mouse strains were derived from the same parental C57BL strain and therefore have been thought to possess a very close genetic relationship. However, we have previously shown that B10RAG2-deficient mice were more susceptible to colitis induced by $\mathrm{CD} 4{ }^{+} \mathrm{CD} 45 \mathrm{RB}^{\text {high }} \mathrm{T}$-cell adoptive transfer in comparison to B6-RAG2-deficient mice housed under the same conditions. ${ }^{22}$ In the current manuscript, we explored the causes for unequal disease development in these two closely related mouse strains in the T-cell transfer model of colitis. Our results support an important role of iTregs in the regulation of immune homeostasis and argue that genetic control of DC-derived IL$12 / 23$ controls the balance of iTregs/effector-pathogenic $\mathrm{CD} 4^{+}$ $T$ cells $\left(T_{E}\right)$ early in disease evolution and determines disease outcome.

\section{RESULTS}

Increased susceptibility of B10-RAG2-deficient mice to colitis is associated with an enhanced colonic accumulation of Th1 and Th17 cells

Adoptive transfer of naive $\mathrm{CD} 4{ }^{+} \mathrm{CD} 25^{-} \mathrm{CD} 45 \mathrm{RB}{ }^{\text {high }} \mathrm{T}$ cells to $\mathrm{B} 10-\mathrm{RAG2}^{-/-}$recipients resulted in significantly more weight loss and higher colitis score compared with B6-RAG2 ${ }^{-1-}$ recipients housed under the same conditions (Figure 1a,b). Consistent with our previously published studies, disease incidence and severity was significantly greater in the B10RAG2 $^{-1-}$ strain. ${ }^{22}$ This was accompanied by a higher rate of $\mathrm{CD} 4{ }^{+}$T-cell accumulation in the colon of the B10-RAG2 ${ }^{-1-}$ recipients (Figure 1c), whereas no difference in $\mathrm{T}$-cell accumulation rates was detected in the spleen (Figure 1c).

Analysis of cytokine expression in whole colonic tissue at the study end point ( 7 weeks) showed that mRNA for both IFN- $\gamma$ and IL-17 was very highly expressed in the B10-RAG2 ${ }^{-1-}$ recipients compared with the B6-RAG2 ${ }^{-1-}$ recipients (Figure 1d). Similar proportions of infiltrating $\mathrm{CD}^{+}{ }^{+} \mathrm{T}$ cells in the two strains expressed IFN- $\gamma$ (20-25\%), IL-17 (3$5 \%)$, or both $(1-2 \%)$ despite higher absolute $\mathrm{CD}^{+}{ }^{+} \mathrm{T}$-cell numbers infiltrating the colon of the B10-RAG2 ${ }^{-1-}$ strain (Figure 1c,e). Therefore, the $\mathrm{B} 10-\mathrm{RAG}^{-1-}$ recipients accumulated more effector T-cell populations that have been previously shown to be colitogenic in this model. ${ }^{8,23,24}$

\section{Imbalance of pathogenic and Tregs early after T-cell transfer correlates with enhanced disease severity in B10-RAG2 $^{-1-}$ recipients}

We next evaluated whether the genetic difference in disease susceptibility was determined at the level of T-cell priming by studying T-cell differentiation in mesenteric lymph nodes (MLNs) at early time points after T-cell transfer. $\mathrm{CD}^{+}{ }^{+} \mathrm{T}$-cell expansion in the MLNs was significantly greater in the B10$\mathrm{RAG}^{-1-}$ recipients as early as 2 weeks following transfer indicated by the higher frequency and absolute numbers of $\mathrm{CD} 4{ }^{+} \mathrm{TCR} \beta^{+} \mathrm{T}$ cells $\left(\mathrm{CD} 4^{+} \mathrm{T}\right.$-cell receptor $\beta^{+} \mathrm{T}$ cells). This occurred despite the absence of histological evidence of colonic inflammation at this time point in either strain (Figure 2a). In addition, accumulation of $\mathrm{CD}^{+} \mathrm{T}$ cells in the colon was already evident by week 2 , and the differences in the frequency and absolute numbers of $\mathrm{CD} 4{ }^{+} \mathrm{TCR} \beta^{+} \mathrm{T}$ cells were similar to those seen in the MLNs (Figure 2a). Furthermore, we observed that larger proportions of $\mathrm{CD} 4^{+} \mathrm{TCR} \beta^{+}$cells in both the MLNs and the colon were capable of producing IFN- $\gamma$ in the B10 strain at this early time point (Figure $\mathbf{2 b}$ ).

In contrast to these findings, as shown in Figure $2 \mathrm{c}$, we observed significantly higher frequencies of $\mathrm{CD} 4^{+}$Foxp $3^{+}$ Tregs in the MLNs and colons of B6-RAG2 ${ }^{-1-}$ compared with the B10-RAG2 ${ }^{-1-}$ mice 2 weeks after adoptive transfer, both by flow cytometry (Figure 2c) and by in situ staining of MLNs and isolated lymphoid follicles (see Supplementary Figure S1a online). The generation of $\mathrm{CD} 4{ }^{+} \mathrm{Foxp}^{+}$cells in the spleen was inefficient in both the mouse strains and no differences in $\mathrm{CD} 4^{+} \mathrm{Foxp}^{+}$T-cell numbers were found at this site (Figure 2c). At time points later than 2 weeks, the frequency of Foxp $3^{+}$cells observed early after transfer decreased in both the strains most likely due to a differential accumulation of $\mathrm{CD} 4^{+}$ effector cells during the course of disease development. Despite these changes over time, the frequencies of $\mathrm{CD} 4{ }^{+}$Foxp $3^{+}$cells were consistently higher in the MLNs and colons of B6-RAG2 ${ }^{-1-}$ compared with the B10-RAG2 ${ }^{-1-}$ mice (see Supplementary Figure S1b online). Therefore, the differences in disease susceptibility between B10- and B6-RAGs ${ }^{-1-}$ mice were manifest early after adoptive transfer as indicated by the higher accumulation of $\mathrm{T}_{\mathrm{E}}$ and lower accumulation of $\mathrm{CD} 4^{+}$ Foxp $^{+}$Tregs in the B10-RAG2 ${ }^{-1-}$ mice.

Importantly, for these studies, transferred naive $\mathrm{T}$ cells contained negligible Treg contamination, as only $\mathrm{CD} 4{ }^{+}$ $\mathrm{CD} 25^{-}$cells with the brightest CD45RB expression were sorted and used for transfers (see Supplementary Figure S2a online). This suggested that the $\mathrm{CD} 4{ }^{+} \mathrm{Foxp}^{+}$population observed in the recipient mice represent peripherally generated iTregs rather than expansion of contaminating nTregs of the donor. To address this question more directly, we transferred to $\mathrm{RAG}^{-1-}$ mice small numbers of genetically marked Foxp $3^{+}$ $\mathrm{T}$ cells $\left(\mathrm{CD}^{+}{ }^{+} \mathrm{GFP}^{+}\right.$(green fluorescent protein-positive) cells from Foxp3-eGFP mice), at equivalent or higher numbers to those that potentially contaminate our starting $\mathrm{CD} 4{ }^{+} \mathrm{CD} 45 \mathrm{RB}^{\text {high }} \mathrm{T}$-cell populations $(0.02-2 \%)$, together with $\mathrm{CD} 4{ }^{+} \mathrm{CD} 45 \mathrm{RB}^{\text {high }} \mathrm{T}$ cells from wild-type (WT) mice. We then assessed the expansion of $\mathrm{CD}^{+}{ }^{+}$Foxp3-eGFP ${ }^{+}$cells over time. Two weeks following the transfer, negligible frequencies of $\mathrm{CD} 4{ }^{+}$Foxp3-eGFP ${ }^{+}$cells were found in the MLNs (see Supplementary Figure S2b online). We also examined the Foxp3 expression 2 weeks after transfer of CD $4{ }^{+} \mathrm{CD}_{45 \mathrm{RB}^{\text {high }}} \mathrm{Foxp}^{-}{ }^{-}$cells from Foxp3-eGFP mice and 
a

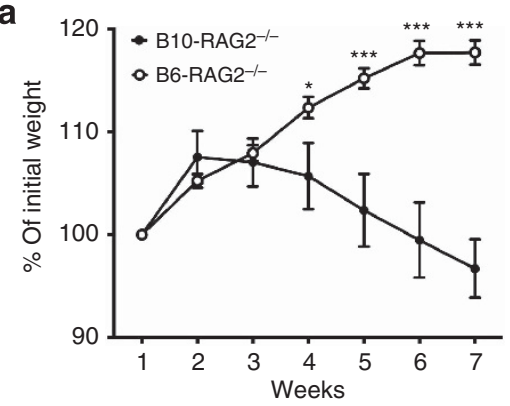

C

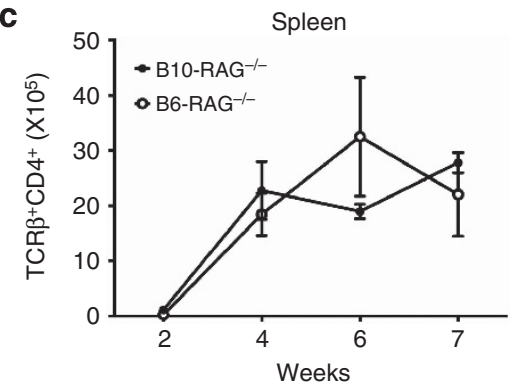

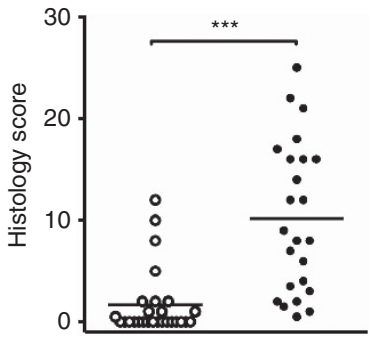

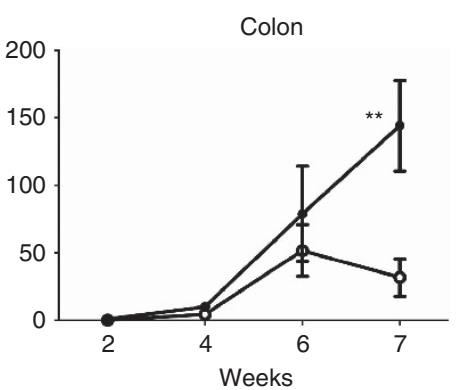

b

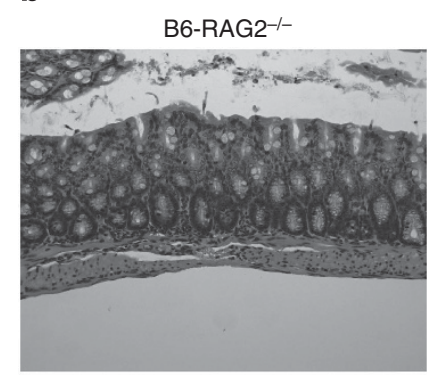

B10-RAG2-1-

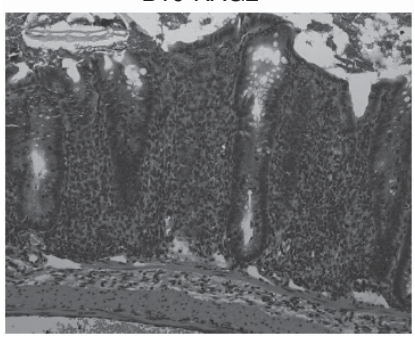

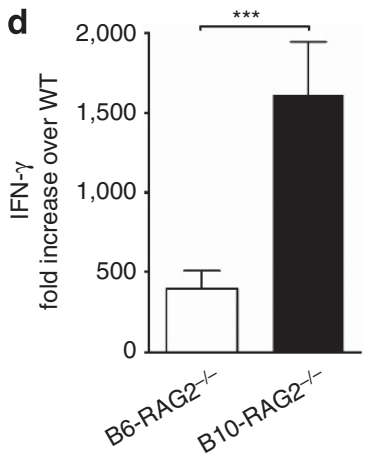

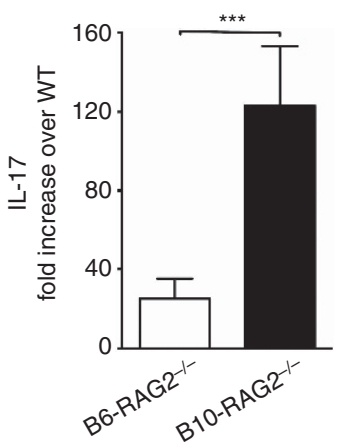

e

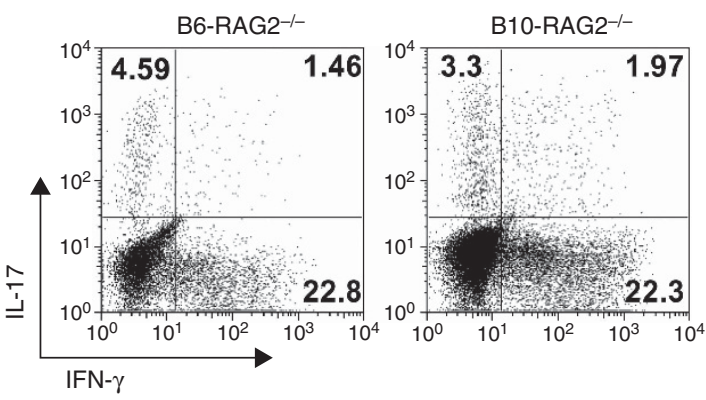

Figure 1 B10-RAG2 ${ }^{-1-}$ recipients are more susceptible to T-cell transfer colitis due to enhanced colonic accumulation of pathogenic T cells. (a) Weight change (left panel) and colonic histology scores (right panel) at study end point (7 weeks) following T-cell adoptive transfer to B6-RAG2 ${ }^{-1-}$ and B10$\mathrm{RAG}^{-1}{ }^{-}$mice. Data shown are mean \pm s.d. of 25 mice per group and representative of at least three independent experiments with $25-30$ mice per group in each. $(b)$ Representative colon histology in B6-RAG2 ${ }^{-1-}($ score $=2)$ and B10-RAG2 ${ }^{-1-}($ score $=25)$ mice at the study end point $($ hematoxylin and eosin-staining with original magnification $\times 40)$. (c) Total numbers of CD4 ${ }^{+}$TCR $\beta^{+}$cells isolated from the indicated organs at the indicated time points after T-cell transfer. Data are mean \pm s.d. of five mice per group per time point and representative of at least three independent experiments showing similar results with 20 mice per group in each experiment. (d) Real-time reverse-transcriptase-PCR analysis of interferon- $\gamma$ (IFN- $\gamma$ ) and interleukin-17 (IL-17) gene expression in the colonic tissue at the study end point. Data are generated as mean fold increase \pm s.d., normalized to GAPDH ( $\left.2^{\Delta \Delta C t}\right)$ of 38 and 33 animals per group in duplicate from two independent experiments. (e) Cytokine production by $\mathrm{CD} 4^{+} \mathrm{TCR}^{+}$lymphocytes isolated from the colonic lamina propria of B6- and B10-RAG2 ${ }^{-1-}$ mice at the study end point and stimulated ex vivo for $6 \mathrm{~h}$ in the presence of phorbol 12-myristate 13-acetate/ ionomycin. Plots are representative of at least three independent experiments with at least 20 pooled colons per group in each experiment. Asterisks indicate statistically significant difference between the two strains $\left({ }^{* *} P<0.01,{ }^{* * *} P<0.001\right)$. TCR, T-cell receptor; WT, wild type.

found an equivalent percentage of $\mathrm{CD} 4{ }^{+} \mathrm{Foxp}^{-}-\mathrm{eGFP}^{+}$cells to those found following transfer of $\mathrm{CD} 4{ }^{+} \mathrm{CD} 25^{-} \mathrm{CD} 45 \mathrm{RB}^{\text {high }}$ cells from WT mice (see Supplementary Figure S2b online). These data argue that Foxp3 ${ }^{+} \mathrm{T}$ cells found after transfer of $\mathrm{CD} 4{ }^{+} \mathrm{CD} 45 \mathrm{RB}{ }^{\text {high }} \mathrm{T}$ cells represent Tregs induced de novo from transferred naive $\mathrm{T}$ cells.

To address the possibility that the induced Foxp ${ }^{+}$Tregs are important for the control of proliferation and differentiation of effector T cells in this model, we transferred WT or Foxp3deficient $\mathrm{CD} 4{ }^{+} \mathrm{CD} 45 \mathrm{RB}^{\text {high }} \mathrm{T}$ cells (isolated from WT/scurfymixed bone marrow chimeric mice) into B6-RAG2 ${ }^{-/}$ recipients. Mice that received Foxp3-deficient naive $\mathrm{T}$ cells developed worse disease than those transferred with WT
$\mathrm{CD} 4{ }^{+} \mathrm{CD} 45 \mathrm{RB}^{\text {high }} \mathrm{T}$ cells and equivalent to that seen in the B10-RAG2 ${ }^{-1-}$ mice transferred with WT cells (Figure 2d). Consistent with these findings, lack of de novo Treg differentiation following the transfer of Foxp3-deficient $\mathrm{CD} 4^{+} \mathrm{CD} 45 \mathrm{BR}^{\text {high }} \mathrm{T}$ cells into in $\mathrm{B} 6-\mathrm{RAG}^{-1-}$ mice resulted in enhanced Th1 effector cells in inflamed colonic tissue (Figure 2e). These data indicate that defective peripheral generation of iTregs is able to alter disease severity.

\section{Treg/ $T_{E}$ differentiation and colitis severity is due to host and not T-cell-dependent strain differences}

We next explored whether the differential induction of $T_{E}$ and Tregs and disease outcome in the two strains was due to 
a

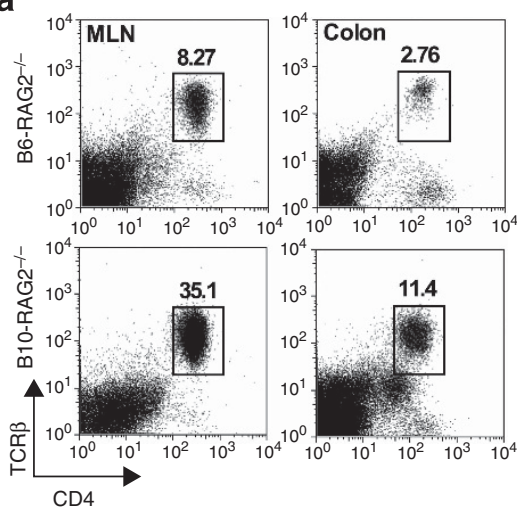

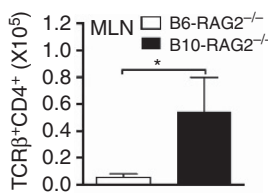

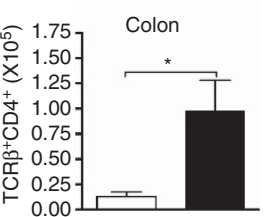

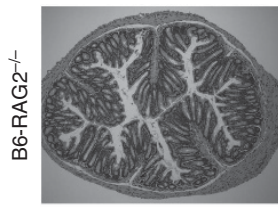

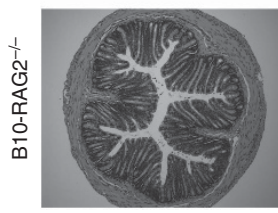

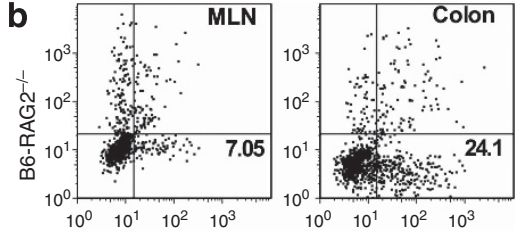
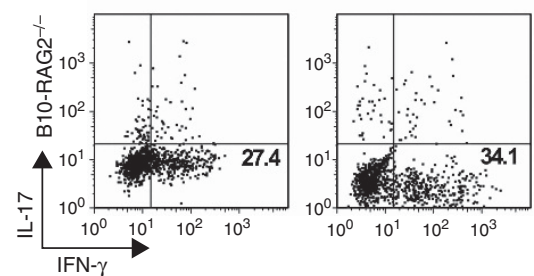

C
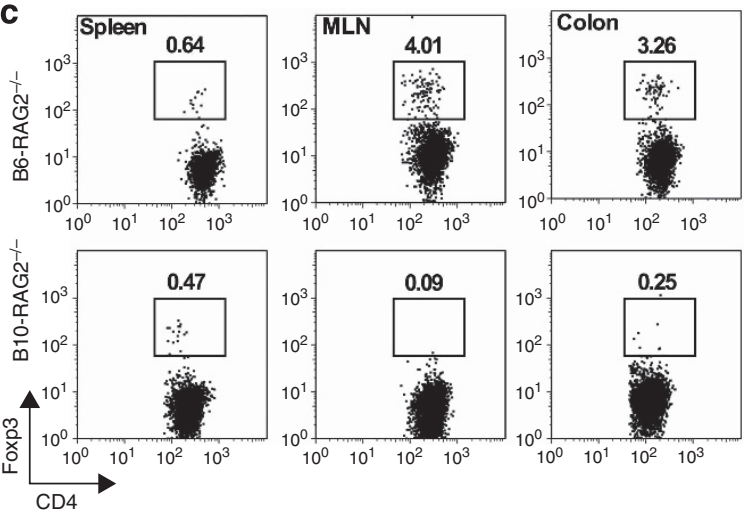

d

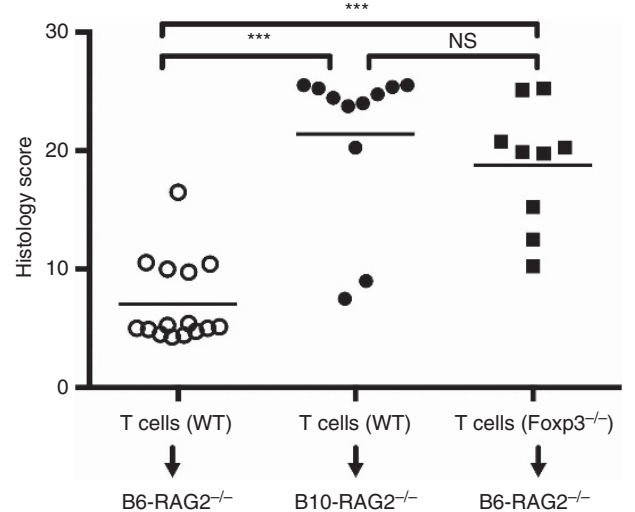

e
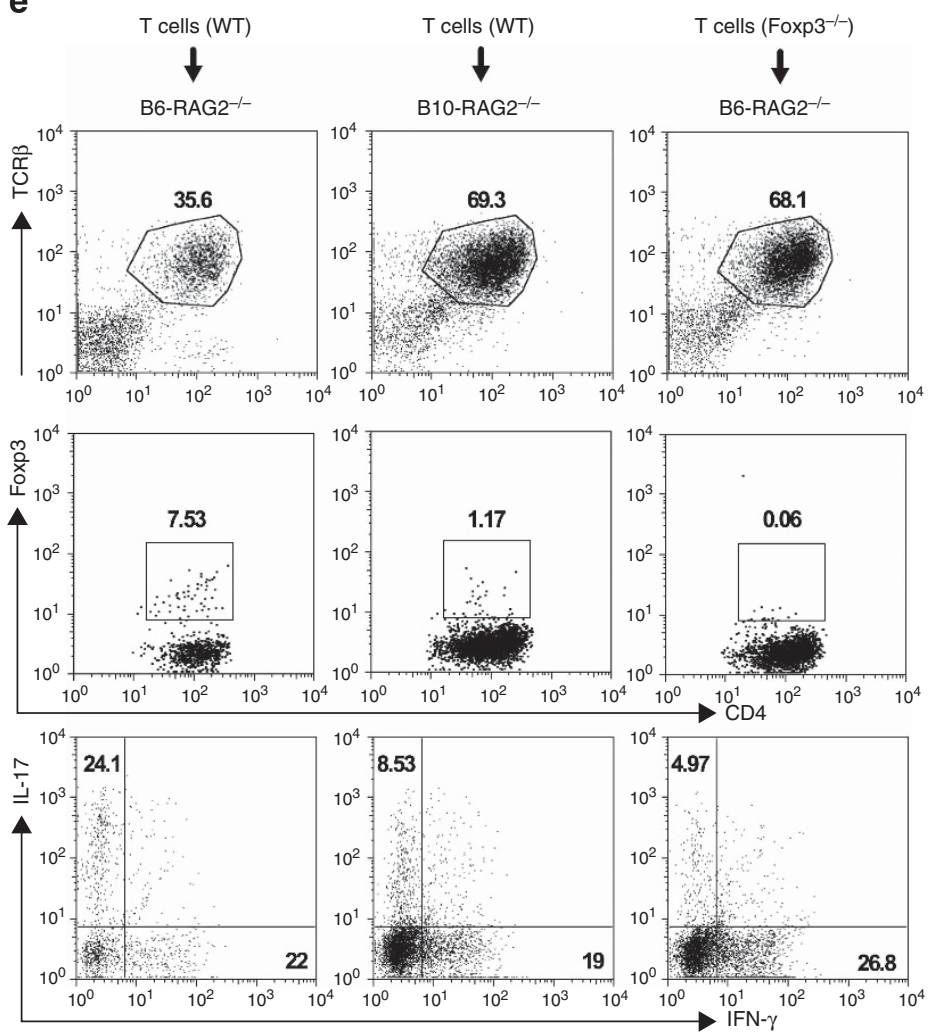

Figure 2 Disease severity associates with the early local balance of CD4 ${ }^{+}$Foxp3 ${ }^{+}$T cells and T helper type 1 (Th1)/17 cells, which depends on the ability to generate induced regulatory T cells. (a) Flow cytometry analysis (left panel) of lymphocytes, gated based on characteristic light-scatter properties, isolated from the indicated organs of B6- and B10-RAG2 ${ }^{-1-}$ recipients at week 2 after T-cell transfer. Plots are representative of five independent experiments with 3-5 pooled mice in each. Middle panel: total numbers of CD4 ${ }^{+} \mathrm{TCR}^{+} \mathrm{T}$ cells isolated from the indicated organs at 2 weeks after T-cell transfer. Results are mean \pm s.e.m. of three independent experiments with cells pooled from three mice in each. Right panel: Representative colon histology from at least three independent experiments of B6- and B10-RAG2 ${ }^{-1-}$ recipients at 2 weeks after T transfer (hematoxylin and eosin-staining with original magnification $\times 10$ ). (b) Cytokine production by CD4 ${ }^{+} \mathrm{TCR} \beta^{+}$lymphocytes isolated from the indicated organs of B6- and B10-RAG2 ${ }^{-1-}$ mice at 2 weeks after T transfer and stimulated ex vivo for $6 \mathrm{~h}$ in the presence of phorbol 12-myristate 13-acetate (PMA)/ionomycin. (c) Percentage of Foxp3 ${ }^{+}$cells gated on $\mathrm{CD} 4^{+} \mathrm{TCR} \beta^{+}$T cells isolated from the indicated organs at 2 weeks after $\mathrm{T}$ transfer. Plots $\mathbf{b}$ and $\mathbf{c}$ are representative of five independent experiments with cells pooled from 3-5 mice per group in each experiment. (d) Histology scores of Rag-deficient mice that were given Foxp3 ${ }^{-1-}$ or wild-type (WT) $C D 4{ }^{+} \mathrm{CD}_{25}{ }^{-}$CD45RB ${ }^{\text {high }} \mathrm{T}$ cells. Scores are mean \pm s.d. of 9-15 mice in each group and representative of two independent experiments with similar numbers of mice in each group. (e) Percentage of $\mathrm{CD} 4^{+} \mathrm{TCR} \beta^{+}$(upper panel) and Foxp3 ${ }^{+}$(middle panel) lymphocytes, gated based on characteristic light-scatter properties, isolated from the mesenteric lymph nodes (MLNs) of B6- and B10-RAG2 ${ }^{-1-}$ recipients given Foxp3 ${ }^{-1-}$ or WT CD4 ${ }^{+}$CD25 ${ }^{-}$CD45RB ${ }^{\text {high }}$ T cells at study end point (7 weeks). Lower panel: cytokine production by CD4 ${ }^{+}$TCR $\beta^{+}$lymphocytes isolated from the MLNs of B6- and B10-RAG2 ${ }^{-1-}$ mice at the study end point and stimulated ex vivo for $6 \mathrm{~h}$ in the presence of PMA/ionomycin. Plots are representative of two independent experiments with 9-15 mice per group in each. Asterisks indicate statistically significant difference between the two strains $\left({ }^{\star} P<0.05\right.$, ${ }^{\star * \star} P<0.001$, not significant (NS): $P>0.05$ ). TCR, T-cell receptor.

T-cell- or host-dependent factors. To address this issue, we transferred $\mathrm{CD} 4{ }^{+} \mathrm{CD} 25^{-} \mathrm{CD} 45 \mathrm{RB}^{\text {high }} \mathrm{T}$ cells from either B10 or B6 WT animals to either B6-RAG2 ${ }^{-1-}$ or B10-RAG2 ${ }^{-1-}$ hosts. As shown in Figure 3, B10-RAG2 ${ }^{-1-}$ recipients suffered maximum weight loss (Figure 3a) and developed severe colitis (Figure $\mathbf{3 b}$ ) regardless of the origin of the donor 
a
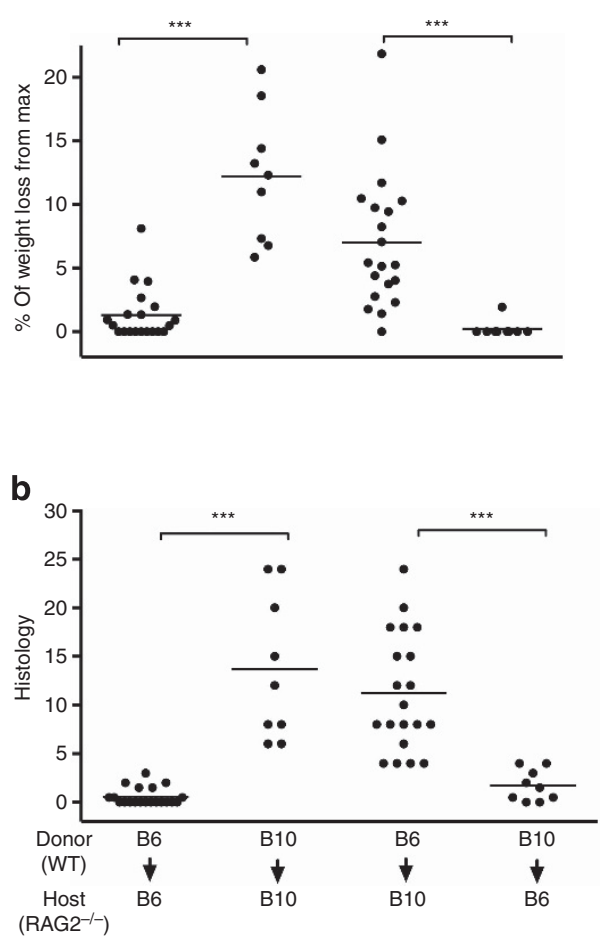

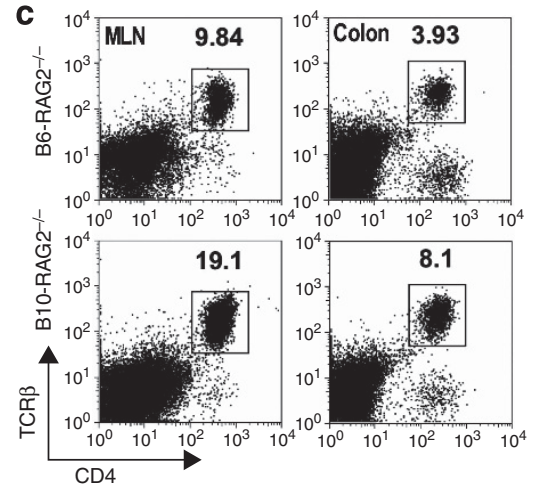

e
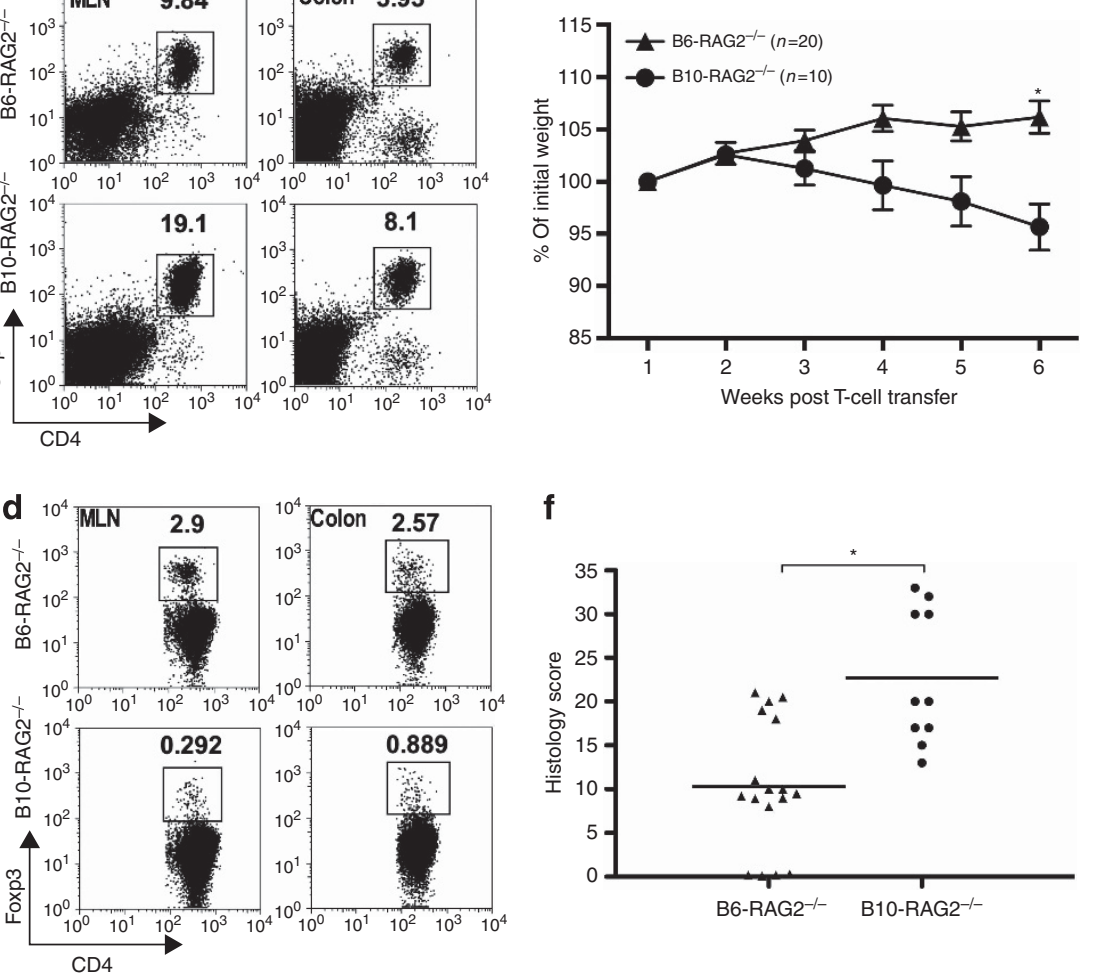

f

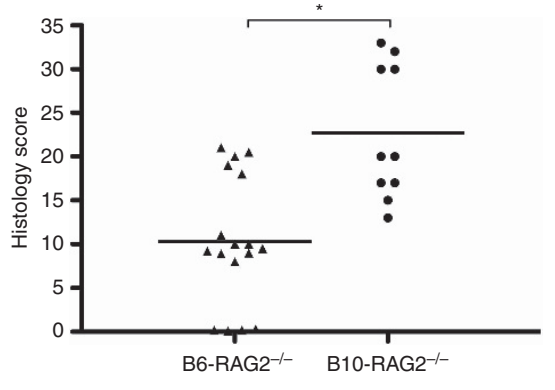

Figure 3 Differential induced regulatory T cells/pathogenic T-cell balance and disease severity is host-dependent and T-cell- and antigen-independent. (a) Weight change and (b) histology scores 7 weeks post-transfer of naive T cells from B6 donors to B10-RAG ${ }^{-1-}$ recipients and vise versa. One representative of two independent experiments with similar results is shown (9-20 mice per group) (c, d) Flow cytometry analysis of lymphocytes, gated based on characteristic light-scatter properties, isolated from the indicated organs of B6-and B10-RAG2 ${ }^{-/-}$recipients of OT-II CD4 ${ }^{+} \mathrm{CD} 45 \mathrm{RB} \mathrm{B}^{\text {high }}$ $T$ cells followed by ovalbumin feeding. One representative of two independent experiments is shown with cells pooled from five mice per group per experiment. (e, f) Timed pregnant female mice from breeding pairs of B6- and B10-RAG ${ }^{-1}$ - were co-housed together with their pups 3 days after giving birth. Following weaning, the pups of each strain were separated, housed under the same conditions, and transferred $C D 4{ }^{+} \mathrm{CD} 45 \mathrm{RB} \mathrm{B}^{\text {high }}$ T cells. Data are mean \pm s.d. of 10-20 mice per group and representative of two independent experiments with similar number of mice in each. (e) Weight change after T-cell transfer, (f) Colonic histology scores at study end point (week 7). Asterisks indicate statistically significant difference between the two strains $\left({ }^{\star} P<0.01,{ }^{* \star *} P<0.001\right)$. MLN, mesenteric lymph node; TCR, T-cell receptor.

T cells. By contrast, B6-RAG2 ${ }^{-1}$ - recipients transferred with $\mathrm{CD} 4{ }^{+} \mathrm{CD} 25^{-} \mathrm{CD}_{45 \mathrm{RB}}{ }^{\text {high }} \mathrm{T}$ cells from either B6 or B10 WT mice had significantly less weight loss and intestinal inflammation than B10-RAG2 $2^{-l-}$ hosts (Figure 3a,b). Notably, B6 and B10 mice share MHC (major histocompatibility complex) haplotypes, and no mice in this study developed signs of graft versus host disease, including skin lesions and hair loss. Furthermore, even if graft versus host disease did occur to some degree in these experimental settings, it is unlikely to have affected only the B10 but not the B6 strain. Therefore, these data indicate that the differential disease outcome in these mouse strains primarily depends on host and not T-cellintrinsic factors.

To confirm these findings, we transferred $\mathrm{CD} 4{ }^{+} \mathrm{T}$ cells from OT-II/RAG1 ${ }^{-1-}$ to B6- or B10-Rag-deficient hosts that were then fed ovalbumin. In this experimental setting, potential effects of $\mathrm{T}$-cell receptor specificity and other differences intrinsic to the B6 or B10 strains in the starting T-cell population are eliminated. ${ }^{25}$ Furthermore, because CD4 ${ }^{+}$ T cells from OT-II/RAG $1^{-1-}$ mice do not contain Foxp3 ${ }^{+}$ Tregs, ${ }^{15,16,26}$ Foxp $3{ }^{+}$Tregs developing after adoptive transfer can be more clearly attributed to differences in iTreg generation rather than differences in the expansion rates of contaminating Foxp $3^{+}$populations. As shown in Figure 3, 14 days after T-cell transfer, OT-II T cells expanded in both the hosts but the frequencies of $\mathrm{CD} 4{ }^{+} \mathrm{TCR}^{+}$T cells were twofold higher in the B10- than in the B6-RAG2 ${ }^{-/-}$hosts (Figure 3c). This was accompanied by higher absolute numbers of $\mathrm{CD} 4{ }^{+} \mathrm{TCR} \beta^{+}$ cells isolated from the MLN (10-20fold) or colon (2-3-fold) of B10- compared with B6-RAG2 ${ }^{-/}$mice (see Supplementary Figure S2c online). By contrast, the frequencies of Foxp $3^{+}$ Tregs were substantially lower in the B10- than in the B6-RAG2 ${ }^{-/-}$hosts (Figure 3d).

\section{Differences in IL-12/23 production by host CD103 ${ }^{+}$DCs regulate the ratio of pathogenic and Tregs and colitis outcome}

In addressing the host-specific factors that influence these differential effects on effector and Tregs expansion and differentiation, we first began to address the possibility that the differences in intestinal commensal bacteria may influence disease development. As the acquisition of intestinal commensal bacteria occurs at weaning and is primarily affected by early environmental rather than genetic factors, ${ }^{27}$ co-nursing, 
during which newborn mice suckle from both the mothers, should minimize commensal microbial differences between the two strains. This is particularly true for segmented filamentous bacteria and Helicobacter sp. that are horizontally transferred and can affect colitis induction. As shown in Figure 3e,f, co-weaning (and co-housing) did not affect the severity of colonic inflammation in the two strains.

We next addressed the possibility that differences in $\mathrm{CD}_{103}{ }^{+}$ or $\mathrm{CD} 103^{-}$DC number or function could account for the different disease patterns. Previous studies have shown that in steady-state conditions, $\mathrm{CD} 4^{+}$Foxp ${ }^{+}$Treg cells are preferentially induced in the GALT by $\mathrm{CD}_{103}{ }^{+}$DCs via their production of TGF- $\beta$ and retinoic acid. ${ }^{15-17}$ By contrast, $\mathrm{CD} 103^{-}$ DCs from GALT drive Th1 cell differentiation and have been associated with IL-23 production. ${ }^{15}$ However, during colitis, $\mathrm{CD} 103^{+}$DCs become more inflammatory and can drive effector rather than Treg differentiation. ${ }^{28}$ Therefore, we examined the phenotype and function of DC populations in the MLNs of B6and B10-RAG2 ${ }^{-1-}$ mice 2 weeks after T-cell transfer. We found no difference in the percentage of total $\mathrm{CD} 11 \mathrm{c}^{+} \mathrm{MHCII}^{\text {high }}$ cells or of CD11c ${ }^{+} \mathrm{MHCII}^{\text {high }} \mathrm{CD} 103^{-}$or $\mathrm{CD}_{103}{ }^{+}$cells in the MLNs between the two strains (see Supplementary Figure $\mathbf{S} 3$ online). By contrast, when we examined cytokine production by quantitative real-time reverse-transcriptase-PCR, fluorescenceactivated cell sorter (FACS)-purified $\mathrm{CD} 11 \mathrm{c}^{+} \mathrm{CD} 103^{+}$DCs from MLNs of B10-RAG2 ${ }^{-/-}$recipients expressed higher levels of IL-6 and IL-23p19 compared with those from B6-RAG2 ${ }^{-1-}$ hosts (Figure 4a).

In vivo strain differences were reproduced in vitro as we observed lower Treg conversion rates and higher frequencies of IFN- $\gamma$-producing T cells, with $\mathrm{CD}_{103}{ }^{+}$DCs isolated from the MLNs of B10-RAG2 ${ }^{-1-}$ hosts in comparison to $\mathrm{CD} 103^{+}$DCs isolated from B6-RAG2 ${ }^{-1-}$ hosts (see Supplementary Figure S3c online). Furthermore, in response to systemic lipopolysaccharide (LPS) challenge, WT B10 mice produced substantially higher amount of serum level of IL-12p70 and IL-23 compared with WT B6 mice (Figure 4b), consistent with previous studies. ${ }^{29,30}$

These data suggested that host DC-derived IL-12 and/or IL23 production might be involved in controlling the balance of pathogenic to Tregs observed in the two strains. To address this possibility, we treated B6- and B10-RAG2 ${ }^{-1-}$ mice with antiIL-12/23p40 antibody on days 0,3 , and 6 after transfer of $\mathrm{CD} 4{ }^{+} \mathrm{CD} 25^{-} \mathrm{CD}^{-} \mathrm{RB}^{\text {high }} \mathrm{T}$ cells (Figure $4 \mathrm{c}$ ). Two weeks after T-cell transfer, neutralization of IL-12/23 resulted in an increased percentage of iTregs in the B10-RAG2 ${ }^{-1-}$ MLN accompanied with a decreased percentage of CD $4^{+} \mathrm{TCR} \beta^{+} \mathrm{T}_{\mathrm{E}}$ (Figure 4d). This early increase of iTregs in the MLNs of the B10-RAG2 ${ }^{-1-}$ strain was associated with decreased numbers of IFN- $\gamma$-producing CD4 T cells at the study end point and was able to reverse colitis pathology and equalize disease severity for the two strains (see Supplementary Figure S4 online).

Taken together, the data presented in this manuscript indicate that disease outcome in the T-cell transfer model of colitis depends on the balance of iTreg and $\mathrm{T}_{\mathrm{E}}$ cell differentiation from naive $\mathrm{T}$ cells in the GALT early following T-cell transfer. The balance of iTregs and $\mathrm{T}_{\mathrm{E}}$ induction is affected by the genetic background of the mice and is likely linked to the intrinsic ability of local DCs and especially the MLNs CD103 ${ }^{+}$ DCs to guide T-cell differentiation via the production of IL-12 and IL-23 axis.

\section{DISCUSSION}

In the present manuscript, we confirmed the differential outcome of experimental colitis in two genetically similar RAG2-deficient mouse strains given $\mathrm{CD} 4{ }^{+} \mathrm{CD} 45 \mathrm{RB}^{\text {high }} \mathrm{T}$ cells. ${ }^{22}$ By closely monitoring the fate of the injected naive $\mathrm{T}$ cells, we showed that severe disease observed in B10-RAG2 ${ }^{-1-}$ mice correlated with the enhanced accumulation of effector/ pathogenic $\mathrm{CD} 4{ }^{+} \mathrm{T}$ cells $\left(\mathrm{T}_{\mathrm{E}}\right)$ in the MLNs and colonic lamina propria compared with less susceptible B6-RAG2 ${ }^{-1-}$ mice.

Inflammation in this T-cell-mediated model of inflammatory bowel disease is dependent on host IL-23 and T-cell expression of IFN- $\gamma$ and T-bet. However, the precise role of Th17 cells and IL-17A/F is more controversial. Although the disease is also dependent on T-cell expression of ROR $\gamma \mathrm{t}$, the "master regulator" for Th17 cell differentiation, blocking IL-17 signalling pathways with antibodies or $\mathrm{T}$ cells from $\mathrm{KO}$ mice can result in equivalent, less, or more severe disease..$^{5-7}$ Furthermore, IL-17-producing ROR $\gamma$ t-positive cells may give rise to IL- $17^{+} / \mathrm{IFN}^{-g^{+}}$, or even IL- $17^{-} / \mathrm{IFN}-\mathrm{g}^{+}$cells in this model under the influence of IL-23, implicating Th17 cells as possible precursors for pathogenic IFN- $\gamma$-producing $\mathrm{T}$ cells in vivo. ${ }^{24}$ Similarly, Crohn's disease in humans has been associated with exacerbated Th1 and Th17 responses, with a clear role for Th1 cells and IFN- $\gamma$ and less clear role for Th17 cells. ${ }^{1,31-33}$ Interestingly, in the current studies, enhanced disease in the B10-Rag2 ${ }^{-1-}$ mice was associated not with a skewed $\mathrm{T}_{\mathrm{E}}$ response but with an equivalently enhanced accumulation of IFN- $\gamma^{+}$and IL- $17^{+}$and IFN- $\gamma^{+}$ IL- $17^{+} \mathrm{T}_{\mathrm{E}}$ cells.

To understand whether the enhanced $\mathrm{T}_{\mathrm{E}}$-cell accumulation in the B10-Rag2 ${ }^{-1-}$ mice was due to intrinsic effects on T-cell priming, we measured T-cell differentiation in the MLNs early after T-cell transfer and before the development of colitis in either strain. We found that $\mathrm{T}_{\mathrm{E}}$-cell differentiation was enhanced and iTreg differentiation was inhibited in the MLN of B10-Rag2 ${ }^{-1-}$ when compared with the B6-Rag2 ${ }^{-1-}$ mice. Furthermore, using Foxp3-deficient $\mathrm{CD} 4{ }^{+} \mathrm{CD} 45 \mathrm{RB}^{\text {hi }} \mathrm{T}$ cells, we demonstrated that defects in peripheral iTreg induction were sufficient to modify disease outcome in the less susceptible B6-RAG2 ${ }^{-1-}$ mice, consistent with a previous report. ${ }^{21}$ These studies implicated strain-specific differences in T-cell priming of $\mathrm{T}_{\mathrm{E}}$ and iTregs between $\mathrm{B} 10$ and $\mathrm{B} 6$ strains, and provided essential support for the ability of iTregs to directly control immunological homeostasis to commensal bacteria.

Naive T cells can differentiate into Treg, Th1, or Th17 cells depending on the cytokine milieu present during $\mathrm{T}$-cell priming. In this regard, TGF- $\beta$ signals have a primary regulatory role. Specifically, in Th1-polarizing conditions, TGF- $\beta$ can restrain Th1 differentiation and induce Foxp3 

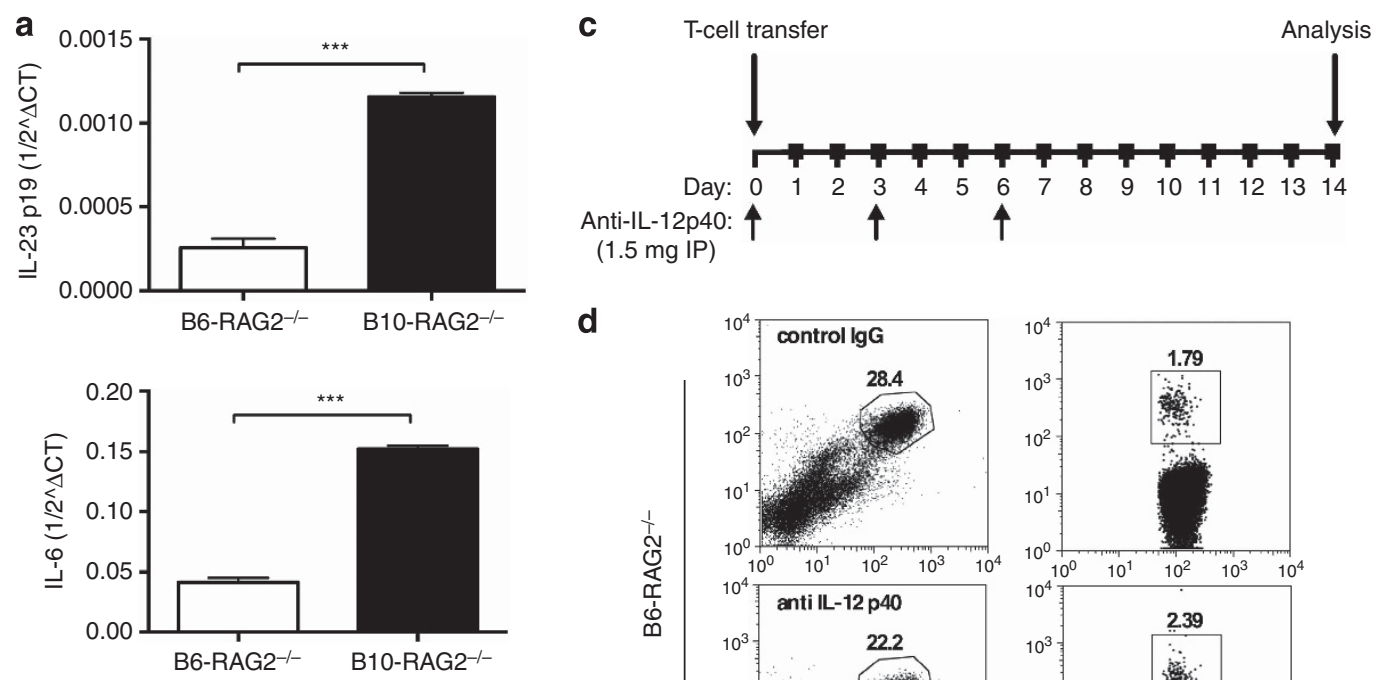

d
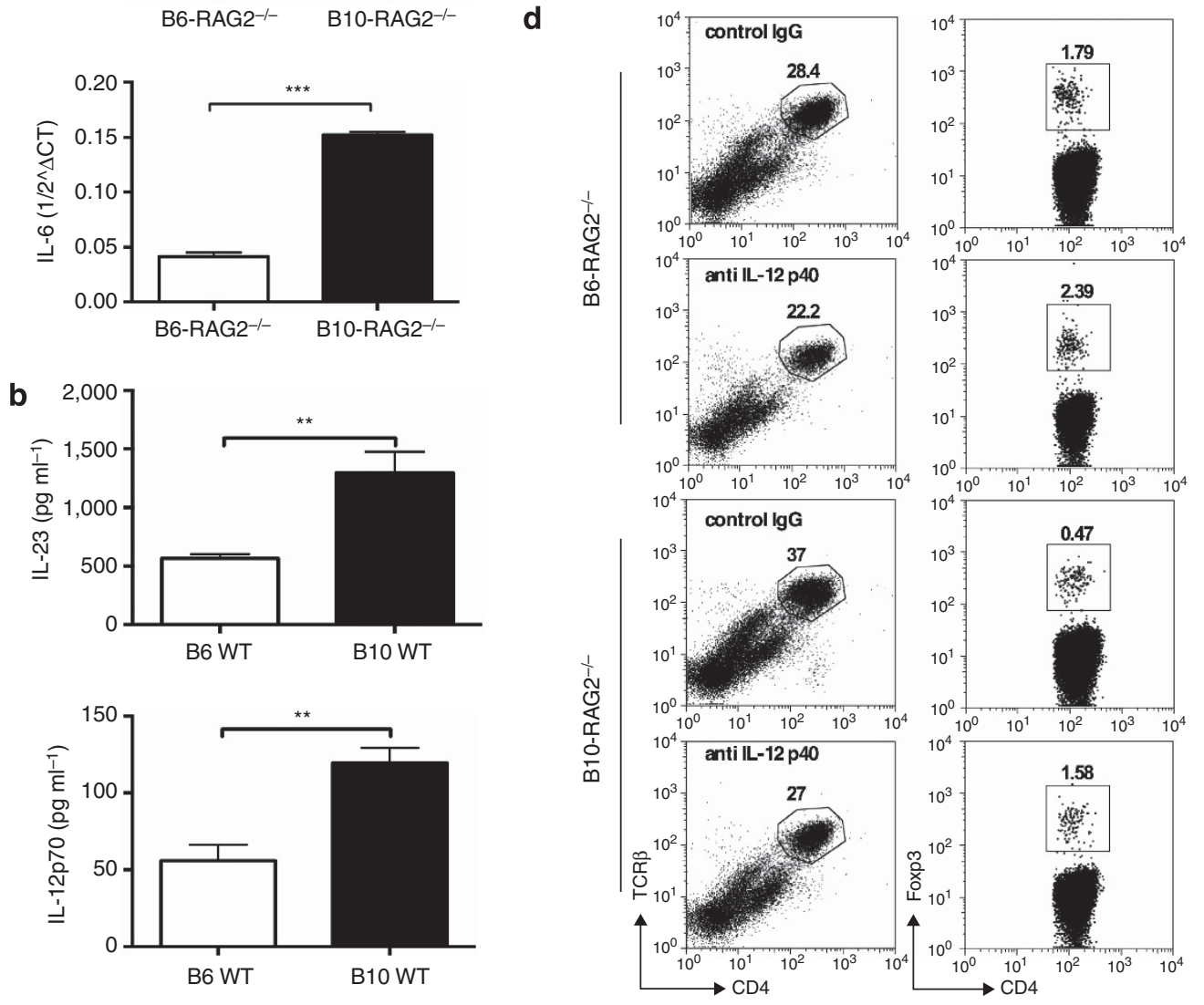

Figure 4 Host CD103 ${ }^{+}$dendritic cell differences in interleukin-12 (IL-12)/23 production likely affect the proportions of pathogenic and regulatory T cells. (a) IL-23 and IL-6 mRNA expression by unstimulated FACS (fluorescence-activated cell sorter)-sorted MHCII ${ }^{\text {high }} \mathrm{CD}_{11 \mathrm{C}^{+}} \mathrm{CD} 103^{+}$dendritic cells freshly isolated from the mesenteric lymph nodes (MLNs) of B6- and B10-RAG2 ${ }^{-1}$ mice 2 weeks following adoptive transfer of CD4 ${ }^{+}$CD25 ${ }^{-}$CD45RB ${ }^{\text {high }}$ T cells. Data shown are mean \pm s.d. of two independent experiments (IL-23p19) with pooled cells from 10 mice per group in each and mean \pm s.d. of triplicate assays (IL-6) representative of three independent experiments with 10 mice per group in each. (b) Serum IL-12p70 and IL-23 following intraperitoneal (IP) injection of lipopolysaccharide. Results represent mean \pm s.d. of three mice per group from two independent experiments (IL-23) and mean \pm s.d. of five mice per group from at least three independent experiments (IL-12p70). (c) Study design of anti-IL-12/23p40 treatment. (d) Flow cytometry analysis of lymphocytes, gated based on characteristic light-scatter properties, isolated from the MLNs of B6- and B10-RAG2 ${ }^{-1-}$ recipients of CD4 ${ }^{+}$CD25 $5^{-}$CD45RB ${ }^{\text {high }}$ T cells treated with IP injection of $1.5 \mathrm{mg}$ of neutralizing anti-IL-12/23p40 or control immunoglobulin G (IgG). Data shown are representative of two independent experiments with similar results. Cells for analysis are pooled from five mice per group per experiment. Asterisks indicate statistically significant difference between the two strains $\left({ }^{\star \star} P<0.01,{ }^{\star \star \star} P<0.001\right)$. TCR, T-cell receptor; WT, wild type.

expression possibly via the $\mathrm{S}_{1} \mathrm{P}_{1}-\mathrm{mTOR}$ axis and the direct inhibition of T-bet expression. ${ }^{34,35}$ By contrast, in the presence of IL-6, TGF- $\beta$ drives Th17 rather than Foxp3 ${ }^{+}$Treg differentiation, ${ }^{36}$ which is enhanced by IL-23. IL-6 inhibits Foxp3 expression, ${ }^{37,38}$ desensitizes $\mathrm{T}$ cells to Treg-mediated suppression, ${ }^{39}$ and preconditions naive $\mathrm{T}$ cells to respond to IL-23 through induction of the IL-23R during T-cell activation. ${ }^{40}$ Furthermore, despite its direct inhibitory effect on Th1 differentiation, ${ }^{41}$ IL-6 may indirectly enhance Th1 responses through the restriction of iTreg induction, similar to IL-23. ${ }^{42}$ In our model, we found higher levels of IL- 6 and IL23 p19 expression by $\mathrm{CD}_{103}{ }^{+}$DCs isolated from the MLNs of the B10-RAG2 ${ }^{-1-}$ strain as compared with the less susceptible B6-RAG2 ${ }^{-1-}$ hosts, implicating genetic control of $\mathrm{CD} 103^{+}$ DC function as an important determinant of disease outcome.

As IL-23 has been implicated in promoting IL-17 production, Th17 cells have been considered to have an important role in driving IL-23-dependent diseases. However, IL-23 has also been linked to enhanced pathogenic Th1 responses in studies of experimental autoimmune encephalomyelitis, ${ }^{43}$ and murine adoptive transfer colitis, ${ }^{11}$ and has been found to enhance Th1 anti-tumour responses. ${ }^{44}$ Our findings associate high levels of IL-23 with enhanced Th1 as well as Th17 and IFN-g ${ }^{+} \mathrm{IL}_{1}{ }^{+}$ T-cell responses in the more susceptible B10 strain. In this 
regard, Izcue et al., ${ }^{11}$ have shown that transfer of naive T cells to IL23A $A^{-1-} \mathrm{RAG1}^{-1-}$ mice has failed to elicit colitis and has been associated with an increased frequency of $\mathrm{CD} 4{ }^{+}$Foxp $3^{+}$ cells in the intestine. Consistent with these findings, inadequate generation of iTregs observed in our highly susceptible B10$\mathrm{RAG}^{-1-}$ mice was likely due to higher levels of IL-23 produced by this mouse strain, which contributed to the enhanced $\mathrm{T}_{\mathrm{E}}$ responses, resulting in more severe colitis in B10-RAG ${ }^{-1-}$ mice. However, as anti-IL-12/23p40 treatment was able to restore the iTreg population in the most susceptible B10$\mathrm{RAG}^{-1-}$ strain and to dampen the enhanced Th1 response, we cannot, at the present time, rule out an independent role for IL-12p70 in these studies, especially as IL-12 is also able to skew the TGF- $\beta$-dependent iTreg or Th17 developmental program into a Th1-like direction. ${ }^{45}$

Heiseke, et al. ${ }^{46}$ reported that the absence of CCL-17 led DCs to produce less IL-12 and IL-23, which protected CCL-17 ${ }^{-1-}$ mice from severe transfer colitis by allowing the expansion of Tregs rather than de novo induction during colitis development. The study clearly supports a role for IL-12/23 in controlling the expansion of nTregs, (containing iTregs) that contaminated the donor T-cell population. However, the contribution of de novo generated iTregs in the increased Treg frequencies observed in these experiments could not be determined. When $\mathrm{CD} 4{ }^{+} \mathrm{CD}_{4} \mathrm{RB}^{\mathrm{hi}} \mathrm{T}$ cells isolated from WT mice (containing nTregs) or DEREG mice treated with DT (depleted of nTregs cells) were transferred to $\mathrm{RAG1}^{-1-}$ $\mathrm{Ccll}^{\mathrm{E} / \mathrm{E}}$ (IL-23-deficient)-recipient mice, protection from colitis was only seen with the former, and very few Foxp3 ${ }^{+}$ Tregs were found in the colon in the latter, suggesting that $d e$ novo Treg-cell induction was not important. Similarly, studies by Izcue et al. ${ }^{11}$ showed no differences in colitis severity in Rag1 ${ }^{-1-}$ mice given WT or Foxp3-deficient naive T cells. By contrast, consistent with the studies performed here, Haribhai, et $a .^{21}$ have reported a central role for iTregs in controlling colitis in this model by showing that Foxp3-deficient naive $\mathrm{T}$ cells caused more rapid colitis than FACS-sorted Foxp $3^{\text {egfp }}$ negative naive $\mathrm{CD} 4{ }^{+} \mathrm{T}$ cells, the latter of which was associated with the presence of $2-9 \%$ of Foxp $3^{\text {egfp }}+$ cells in the MLNs, indicating induction of Tregs in the MLN.

The particular reasons for these disparate results are not yet clear but could be due to differences in the systems used to eliminate Foxp $3^{+} \mathrm{T}$ cells (DEREG vs. FOXP3- ko vs. scurfy mice) or possibly due to differences in the composition of the commensal microflora between the institutions/mouse colonies, particularly as certain bacterial species, e.g. Clostridia spp., ${ }^{47}$ or Bacteroides fagilis, ${ }^{48}$ can preferentially induce Foxp $3^{+}$ T-cell differenitation. The fact that disease development in the $\mathrm{RAG}^{-1-}$ mice in the studies by Heiseke et al. ${ }^{46}$ was very rapidwith severe disease developing at 2 weeks-would be consistent with the possibility that these mice had less capacity to induce Treg differentiation following transfer of naive $\mathrm{T}$ cells.

We performed several additional experiments that all support a role for iTregs in this model. We could show similar enhanced induction of Foxp ${ }^{+}$Tregs from naive TCR-OTII.2a/RAG1 ${ }^{-/-}$mice transferred into B6 compared with
B10-RAG ${ }^{-1-}$ mice and fed ovalbumin. As TCR-OT-II.2a/ $\mathrm{RAG1}^{-1-}$ mice lack Foxp3 ${ }^{+}$Tregs, these data corroborate the enhanced capacity of B6RAG ${ }^{-1-}$ mice to drive the de novo differentiation of $\mathrm{CD} 44^{+}$Foxp $^{+}$Tregs, rather than simply expansion of nTreg cells. Futhermore, we intentionally added back Foxp $3^{+}$cells at frequencies that could have contaminated naive $\mathrm{T}$ cells isolated by our stringent isolation methods and found that, instead of expanding, directly added nTregs were actually eliminated early after transfer, of yet unclear mechanisms, but this may have been due to a severely limited TCRrepertoire of this miniscule T-cell population. Most likely in our studies both induction and expansion of iTreg cells are increased in the B6 RAG ${ }^{-1-}$ mice, and overall, and the main conclusions are very similar to those performed by Heiseke et al. ${ }^{46}$ Lower levels of IL-12/23 produced in the $\mathrm{RAG1}^{-1-} \mathrm{Ccl1}^{\mathrm{E} / \mathrm{E}}$ and $\mathrm{B} 6 \mathrm{RAG}^{-/-}$mice resulted in increased Treg induction/expansion/accumulation that inhibits effector T-cell accumulation and limits colitis development. Finally, consistent with this conclusion, studies by Ahern, et al. $^{24}$ have demonstrated that IL-23R signalling has a direct cell-intrinsic inhibitory effect on the generation of $\mathrm{CD} 4{ }^{+}$ Foxp $3^{+}$T cells and their production of IL-10 in this model. IL23R-signaling on effector $\mathrm{T}$ cells was also shown to have a cellextrinsic effect on effector T-cell accumulation in the colon, ${ }^{24}$ and we hope to explore possible differences in this mechanism between B6- and B10-RAG ${ }^{-/-}$in the future.

Our findings are also consistent with studies showing that $\mathrm{CD}_{103}{ }^{+}$DCs can lose their tolerogenic properties during colitis development. Thus, "inflammatory" $\mathrm{CD} 103^{+}$DCs generated in the setting of colitis are impaired in their ability to induce Foxp $3^{+}$Tregs and instead favour the emergence of IFN- $\gamma^{+}$and $\mathrm{IL}-17^{+} \mathrm{CD} 4^{+}$T cells. ${ }^{28}$ We were able to reproduce strain-associated in vivo differences by isolating $\mathrm{CD}_{103^{+}}$DCs from the MLNs 2 weeks after transfer. We found that MLN CD103 ${ }^{+}$DCs from both strains were relatively inefficient in converting naive $\mathrm{T}$ cells to Tregs in vitro, possibly associated with phenotyopic changes acquired after adoptive T-cell transfer (see Supplementary Figure S3c online). These findings highlight a key role for $\mathrm{CD}_{103}{ }^{+}$DCs in gut homeostasis by regulating the fate of naive $\mathrm{T}$-cell differentiation towards either iTregs that promote tolerance or Th1/17 effector cells that drive inflammatory responses.

Finally, the current studies provide important information regarding the more generalized susceptibility of B10 (vs. B6) mouse strains to inflammatory disease. Thus, it has been shown that B10 mice are not only highly sensitive to colitis induction in the T-cell-transfer model shown here but also in the TNBS (trinitrobenzene sulfonic acid)-colitis model in Rag2 ${ }^{+1+}$ mice. $^{29,49}$ Furthermore, B10 mice are highly sensitive to models of experimental autoimmune uveitis and experimental skin inflammation when compared with B6 mice. ${ }^{22,50}$

Despite their common origin, the B6 and B10 mouse strains have substantial genetic differences most likely caused by residual allogenicity present in the parental C57 stock at the time of separation. ${ }^{44}$ B6 and B10 strains differ by as much as 20 centimorgan (cM) in segments across the genome. ${ }^{51}$ With 
regard to susceptibility to autoimmune disease, one potentially important difference has been located on Chromosome 11, which contains the ortholog of human IBD5 locus that has been associated with an "extensive and complicated" phenotype of Crohn's disease. ${ }^{52,53}$ This region contains a susceptibility locus (Tnbs2) for colitis induced by intra-rectal administration of TNBS in both the B6 and SJL/J mouse strains and harbors the IL-12p40 gene. $^{29,30}$ Furthermore, increased susceptibility to TNBS-colitis of WT B10 (vs. B6) mice was associated with enhanced production of IL-12p70 and more severe disease in SJL/J mice, with enhanced production of both IL-12 and IL-23 in response to systemic LPS administration. ${ }^{29,30}$ Recently, the genetic polymorphism in the IL-12p40 chain of SJL/J mice was found to directly affect the binding affinity of IL-12p40 to IL12 p35 and IL-23p19 most likely due to conformational changes following differential glycosylation as a consequence of the polymorphism. Zwiers et al. suggested that genetic regulation of IL-12 or IL-23 could be relevant to genetic susceptibility of B10 mice. ${ }^{29,30}$ The current studies support this hypothesis by providing a plausible mechanism connecting the genetic regulation of IL-12 and IL-23 with the differential induction of $\mathrm{T}_{\mathrm{E}}$ and iTreg cells by $\mathrm{CD}_{103^{+}}$DCs.

\section{METHODS}

Animals. C57BL/6 (B6), C57BL/10SgSnAi (B10), C57BL/6-RAG2 ${ }^{-1-}$ $\left(\mathrm{B} 6-\mathrm{RAG}^{-1-}\right), \mathrm{C} 57 \mathrm{BL} / 10-\mathrm{RAG}^{-}{ }^{--}\left(\mathrm{B} 10-\mathrm{RAG}^{-1-}\right)$, and TCROT-II.2a/RAG1 ${ }^{-1-}$ transgenic mice were purchased from Taconic Farms (Germantown, NY). Scurfy mice were kindly provided by Dr Ethan Shevach (NIAID, NIH). For co-weaning experiments, timed pregnant female mice from breeding pairs of B6- and B10-RAG2 ${ }^{-1-}$ were co-housed together with their pups 3 days after giving birth. Future B6-RAG2 ${ }^{-1-}$ and $\mathrm{B} 10-\mathrm{RAG}^{-/-}$recipients freely suckled from mothers of both stains until weaning. All mice were housed under specific pathogen-free conditions at an American Association for the Accreditation of Laboratory Animal Careaccredited animal facility at the NIAID. Experiments conducted were under animal study protocol LMI11E approved by the NIAID Animal Care and Use Committee.

Induction of colitis by adoptive T-cell transfer. Total CD4 ${ }^{+} \mathrm{T}$ cells were isolated from the spleens of $6-8$-week-old female C57BL/6 or $\mathrm{C} 57 \mathrm{BL} / 10$ mice via negative selection using the magnetic activation cell sorter (MACS) CD4 T-cell isolation kit (Miltenyi Biotec, Auburn, CA). Enriched cells were subsequently sorted for $\mathrm{CD} 4{ }^{+} \mathrm{CD} 25^{-}$ CD45RB ${ }^{\text {high }}$ naive T cells using FACS (FACSAriaTM, BD Biosciences, San Jose, CA). In all, $2 \times 10^{5} \mathrm{CD} 4{ }^{+} \mathrm{CD} 25^{-} \mathrm{CD} 45 \mathrm{RB}^{\text {high }}$ cells were transferred intraperitoneally (IP) to recipient 6-8-week-old female RAG2-deficient mice. The development of intestinal inflammation was monitored by weight loss, which correlates with histological evidence of colitis. The study end point was defined by a mean weight loss of $5-10 \%$ from initial weight of B10-RAG2 ${ }^{-/-}$mice that usually occurred 6-8 weeks after adoptive transfer. Colonic inflammation was assessed by previously published scoring systems modified as follows. ${ }^{23}$ In brief, haematoxylin and eosin (H\&E) -stained longitudinal and cross-sections of colons were graded semi-quantitatively for crypt length (0-2), lamina propria cellularity (0-3), and epithelial abnormalities, including goblet cell loss, epithelial hyperplasia, erosions, and ulcerations $(0-3)$. Changes were also scored as to the percentage of area of involvement according to the scale $1=25 \%$, $2=50 \%, 3=75 \%$, and $4=100 \%$. For each analysis, cells collected and pooled from 20-30 animals per group.
Generation of scurfy/WT chimeric mice. B6 SJL mice with congenic marker CD45.1 (Taconic Farms) were irradiated with 900 RAD and subsequently injected with combined bone marrow cells $\left(5 \times 10^{6}\right)$ from 3-week-old scurfy mice and WT B6 SJL mice at 1:1 ratio intravenously. Eight weeks after reconstitution, $\mathrm{CD} 4^{+}$ CD45RB ${ }^{\text {high }} \mathrm{CD} 45.1^{-}$CD 45.2 ${ }^{+}$T cells (Foxp3-deficient) and CD4 ${ }^{+}$ CD 45RB ${ }^{\text {high }} \mathrm{CD} 45.1^{+} \mathrm{CD} 45.2^{-} \mathrm{T}$ cells (Foxp3-sufficient) were FACS sorted from spleen cells and used for transfers.

Adoptive transfer of OT-II T cells and ovalbumin feeding. FACSsorted CD $4{ }^{+}$CD $45 \mathrm{RB}^{\text {high }}$ T cells from 6-8-week-old TCR-OT-II.2a/ $\mathrm{RAG1}^{-1-}$ transgenic mice were transferred IP to 6-8-week-old female RAG2-deficient recipient mice at $4 \times 10^{5}$ cells per mouse. Twenty-four hours after adoptive transfer, mice were given drinking water containing 1.5\% OVA for 5 consecutive days. On day 14, total lymphocytes from MLN and colon were analysed by flow cytometry. For each analysis, cells were collected and pooled from three animals per group.

Cell preparation. Single-cell suspensions from the spleens and MLNs were made by homogenizing the tissue through 100 - and then $40-\mu \mathrm{m}$ strainers (BD Falcon, San Jose, CA) in HBSS (Hank's balanced salt solution; Invitrogen, Carlsbad, CA). Desired cell population, T cells or DCs, was enriched using CD4 T-cell isolation kit for T cells or anti CD11c microbeads for DCs by MACS (Miltenyi Biotec). After enrichment, $\mathrm{CD} 11 \mathrm{c}^{+}$cells were subsequently sorted for CD11c ${ }^{+}$ $\mathrm{MHCII}^{\text {hi }} \mathrm{CD} 103^{+}$subset using FACSAria (BD Biosciences). To obtain lamina propria mononuclear cells, colon tissue was washed in $\mathrm{Ca}^{+}+$ and $\mathrm{Mg}^{+}{ }^{+}$-free HBSS and cut into $0.5-\mathrm{cm}$ pieces. The epithelium was stripped by incubation in HBSS supplemented with 15 mM HEPES (4(2-hydroxyethyl)-1-piperazineethanesulfonic acid), $5 \mathrm{~mm}$ EDTA (Invitrogen), 10\% fetal calf serum (Gemini, West Sacramental, CA), and $1 \mathrm{~mm}$ dithiothreitol (Sigma-Aldrich, St Louis, MO) for $15 \mathrm{~min}$ under vigorous shaking at $37^{\circ} \mathrm{C}$. Remaining tissue was digested in complete Iscove's DMEM (Dulbecco's modified Eagle's medium) containing $0.5 \mathrm{mg} \mathrm{ml}^{-1}$ liberase CI and $30 \mu \mathrm{g} \mathrm{ml}^{-1}$ Dnase I (Roche, Indianapolis, IN) in a shaking incubator at $37^{\circ} \mathrm{C}$ for $1 \mathrm{~h}$. Single-cell suspensions were made by passing digested tissue through 100 - and 40- $\mu \mathrm{m}$ strainers.

Flow cytometry. Cells were stained with the following directly conjugated monoclonal antibodies (mAb): CD4 (RM4-5), TCR $\beta$ (H57-597), CD25 (7D4), IFN- $\gamma$, IL-17, and Foxp3 (FJK-16s; eBioscience, San Diego, CA) and analysed on a FACSCaliber flow cytometer (BD Biosciences) using FlowJo software (FlowJo; Tree Star, Ashland, OR). For intracellular cytokine analysis, cells were stimulated with $0.1 \mu \mathrm{M}$ phorbol 12 -myristate 13 -acetate and $1 \mu \mathrm{M}$ ionomycin (Sigma-Aldrich), plus $10 \mu \mathrm{g} \mathrm{ml}^{-1}$ Brefeldin A (BD Biosciences), for $6 \mathrm{~h}$ at $37^{\circ} \mathrm{C}$ and stained for cytokine production using the BD Cytofix/ CytopermPlus fixation/permeabilization Kit (BD Biosciences). Foxp3 expression was performed using the mouse Treg staining kit (eBioscience) according to the manufacturer's instructions.

Real-time reverse-transcriptase-PCR. Freshly harvested mouse MLN and colon tissues were stored in RNAlater (Ambion, Austin, TX). Total RNA extraction from individual tissue sample was performed using the RNeasy mini kit (QIAGEN, Valencia, CA). cDNA was reverse-transcribed using Superscript III first-strand synthesis kit (Invitrogen) and real-time PCR analysis was performed on the 7,900HT Fast Real-Time PCR instrument (Applied Biosystems, Carlsbad, CA) using FAM-labeled gene-specific probes and primers (Applied Biosystems). Relative target gene expression is expressed as 1/ $2^{\Delta \Delta \mathrm{Ct}}$ with GAPDH (glyceraldehyde 3-phosphate dehydrogenase) as endogenous control and non-transferred mice as reference and Ct is threshold cycle.

LPS challenge. B6 and B10 WT mice were injected (IP) with a sublethal $(300 \mu \mathrm{g})$ dose of Salmonella enteritidis LPS (Sigma-Aldrich) dissolved in phosphate-buffered saline. Serum level of IL-12p70 or IL- 
23 was measured $6 \mathrm{~h}$ after injection by ELISA (R\&D Systems, Minneapolis, MN) according to the manufacturer's instructions. Five mice per group were analysed.

Anti-IL12/23-p40 treatment. B6- and B10-RAG2 ${ }^{-1-}$ mice were injected with anti-IL-12/23 p40 (clone C17.8, originally provided by Giorgio Trinchieri) or control immunoglobulin $\mathrm{G}$ (1.5 mg per mouse per dose) IP on the day before $\mathrm{CD} 4{ }^{+} \mathrm{CD} 25^{-} \mathrm{CD} 45 \mathrm{RB}^{\text {high }}$ naive $\mathrm{T}$ cells transfer, then subsequently these mice were given the same dose IP on day 3 and day 6 after T-cell transfer. Two weeks after T-cell transfer, MLNs were taken out from these mice and Foxp $3^{+}$-expressing T cells were assessed by FACS.

Statistical analysis. Comparisons between groups were performed using Student's $t$-test for independent samples or Mann-Whitney $U$ test when appropriate. For the experiments with multiple time points, the two-way ANOVA was used for the analysis of differences between the two strains followed by Bonferroni post-hoc tests. Statistical significance was established at $P<0.05$. GraphPad Prism 4.03 software was used for analysis (GraphPad Software, San Diego, CA).

SUPPLEMENTARY MATERIAL is linked to the online version of the paper at http://www.nature.com/mi

\section{ACKNOWLEDGEMENTS}

Funding for these studies was provided by the Division of Intramural Research, NIAID, NIH, Bethesda, MD, USA. We thank Ethan Shevach and Eva Huter for their help with the scurfy mouse experiments, and Ivan Fuss for providing anti-IL12p40 antibodies. We would also like to thank the Flow Cytometry Unit, Research Technologies Branch, NIAID for their help with flow cytometric sorting.

\section{DISCLOSURE}

The authors declare no conflict of interest.

c) 2013 Society for Mucosal Immunology

\section{REFERENCES}

1. Xavier, R.J. \& Podolsky, D.K. Unravelling the pathogenesis of inflammatory bowel disease. Nature 448, 427-434 (2007).

2. Bouma, G. \& Strober, W. The immunological and genetic basis of inflammatory bowel disease. Nat. Rev. Immunol. 3, 521-533 (2003).

3. Strober, W., Fuss, I.J. \& Blumberg, R.S. The immunology of mucosal models of inflammation. Annu. Rev. Immunol. 20, 495-549 (2002).

4. Elson, C.O. et al. Monoclonal anti-interleukin 23 reverses active colitis in a Tcell-mediated model in mice. Gastroenterology 132, 2359-2370 (2007).

5. Leppkes, M. et al. RORgamma-expressing Th17 cells induce murine chronic intestinal inflammation via redundant effects of IL-17A and IL-17F. Gastroenterology 136, 257-267 (2009).

6. Yen, D. et al. IL-23 is essential for $T$ cell-mediated colitis and promotes inflammation via IL-17 and IL-6. J. Clin. Invest 116, 13101316 (2006).

7. O'Connor, W. Jr. et al. A protective function for interleukin 17A in T cellmediated intestinal inflammation. Nat. Immunol 10, 603-609 (2009).

8. Hue, S. et al. Interleukin-23 drives innate and T cell-mediated intestinal inflammation. J. Exp. Med 203, 2473-2483 (2006).

9. Kullberg, M.C. et al. IL-23 plays a key role in Helicobacter hepaticus-induced T cell-dependent colitis. J. Exp. Med 203, 24852494 (2006).

10. Uhlig, H.H. et al. Differential activity of IL-12 and IL-23 in mucosal and systemic innate immune pathology. Immunity 25, 309-318 (2006).

11. Izcue, A. et al. Interleukin-23 restrains regulatory Tcell activity to drive Tcelldependent colitis. Immunity 28, 559-570 (2008).

12. Mottet, C., Uhlig, H.H. \& Powrie, F. Cutting edge: cure of colitis by CD4 + CD25 + regulatory T cells. J. Immunol. 170, 3939-3943 (2003).

13. Powrie, F., Correa-Oliveira, R., Mauze, S. \& Coffman, R.L. Regulatory interactions between CD45RBhigh and CD45RBlow CD4 $+\mathrm{T}$ cells are important for the balance between protective and pathogenic cellmediated immunity. J. Exp. Med 179, 589-600 (1994).

14. Bluestone, J.A. \& Abbas, A.K. Natural versus adaptive regulatory T cells. Nat. Rev. Immunol. 3, 253-257 (2003).

15. Coombes, J.L. et al. A functionally specialized population of mucosal CD103 + DCs induces Foxp3 + regulatory T cells via a TGF-beta and retinoic acid-dependent mechanism. J. Exp. Med 204, 1757-1764 (2007).

16. Sun, C.M. et al. Small intestine lamina propria dendritic cells promote de novo generation of Foxp3 T reg cells via retinoic acid. J. Exp. Med 204, 1775-1785 (2007).

17. Mucida, D. et al. Reciprocal $\mathrm{TH} 17$ and regulatory $\mathrm{T}$ cell differentiation mediated by retinoic acid. Science 317, 256-260 (2007).

18. Curotto de Lafaille, M.A., Lino, A.C., Kutchukhidze, N. \& Lafaille, J.J. CD25- T cells generate CD25 + Foxp3 + regulatory T cells by peripheral expansion. J. Immunol. 173, 7259-7268 (2004).

19. Liang, S., Alard, P., Zhao, Y., Parnell, S., Clark, S.L. \& Kosiewicz, M.M. Conversion of CD4 + CD25- cells into CD4 + CD25 + regulatory T cells in vivo requires B7 costimulation, but not the thymus. J. Exp. Med. 201, 127-137 (2005).

20. Thornton, A.M. et al. Expression of Helios, an Ikaros transcription factor family member, differentiates thymic-derived from peripherally induced Foxp3 + T regulatory cells. J. Immunol. 184, 3433-3441 (2010).

21. Haribhai, D. et al. A central role for induced regulatory T cells in tolerance induction in experimental colitis. J. Immunol. 182, 3461-3468 (2009).

22. Leon, F. et al. Antibodies to complement receptor 3 treat established inflammation in murine models of colitis and a novel model of psoriasiform dermatitis. J. Immunol. 177, 6974-6982 (2006).

23. Asseman, C., Mauze, S., Leach, M.W., Coffman, R.L. \& Powrie, F. An essential role for interleukin 10 in the function of regulatory Tcells that inhibit intestinal inflammation. J. Exp. Med. 190, 995-1004 (1999).

24. Ahern, P.P. et al. Interleukin-23 drives intestinal inflammation through direct activity on T cells. Immunity 33, 279-288 (2010).

25. Lohr, J., Knoechel, B. \& Abbas, A.K Regulatory T cells in the periphery. Immunol. Rev. 212, 149-162 (2006).

26. Kretschmer, K., Apostolou, I., Hawiger, D., Khazaie, K., Nussenzweig, M.C. \& von Boehmer, $H$. Inducing and expanding regulatory $T$ cell populations by foreign antigen. Nat. Immunol. 6, 1219-1227 (2005).

27. Friswell, M.K. et al. Site and strain-specific variation in gut microbiota profiles and metabolism in experimental mice. PLoS One 5, e85842010).

28. Laffont, S., Siddiqui, K.R. \& Powrie, F. Intestinal inflammation abrogates the tolerogenic properties of MLN CD103+ dendritic cells. Eur. J. Immunol. 40, 1877-1883 (2010).

29. Bouma, G., Kaushiva, A. \& Strober, W. Experimental murine colitis is regulated by two genetic loci, including one on chromosome 11 that regulates IL-12 responses. Gastroenterology 123, 554-565 (2002).

30. Zwiers, A. et al. A polymorphism in the coding region of $1112 \mathrm{~b}$ promotes IL-12p70 and IL-23 heterodimer formation. J. Immunol. 186, 3572-3580 (2011).

31. Hovhannisyan, Z., Treatman, J., Littman, D.R. \& Mayer, L. Characterization of interleukin-17-producing regulatory Tcells in inflamed intestinal mucosa from patients with inflammatory bowel diseases. Gastroenterology 140 , 957-965 (2011).

32. Sakuraba, A., Sato, T., Kamada, N., Kitazume, M., Sugita, A. \& Hibi, T. Th1/ Th17 immune response is induced by mesenteric lymph node dendritic cells in Crohn's disease. Gastroenterology 137, 1736-1745 (2009).

33. van Beelen, A.J. et al. Stimulation of the intracellular bacterial sensor NOD2 programs dendritic cells to promote interleukin-17 production in human memory T cells. Immunity 27, 660-669 (2007).

34. Liu, G., Yang, K., Burns, S., Shrestha, S. \& Chi, H. The S1P(1)-mTOR axis directs the reciprocal differentiation of $\mathrm{T}(\mathrm{H}) 1$ and $\mathrm{T}(\mathrm{reg})$ cells. Nat. Immunol. 11, 1047-1056 (2010).

35. Neurath, M.F. et al. The transcription factor T-bet regulates mucosal Tcell activation in experimental colitis and Crohn's disease. J. Exp. Med 195, 1129-1143 (2002).

36. Zhou, L., Chong, M.M. \& Littman, D.R. Plasticity of CD4 + T cell lineage differentiation. Immunity 30, 646-655 (2009).

37. Bettelli, E. et al. Reciprocal developmental pathways for the generation of pathogenic effector TH17 and regulatory T cells. Nature 441, 235-238 (2006). 
38. Doganci, A. et al. The IL-6R alpha chain controls lung CD4 + CD25 + Treg development and function during allergic airway inflammation in vivo. J. Clin. Invest. 115, 313-325 (2005).

39. Pasare, C. \& Medzhitov, R. Toll pathway-dependent blockade of CD4+ CD25 + T cell-mediated suppression by dendritic cells. Science $\mathbf{2 9 9}$ 1033-1036 (2003).

40. Zhou, L. et al. IL-6 programs $T(H)-17$ cell differentiation by promoting sequential engagement of the IL-21 and IL-23 pathways. Nat. Immunol. 8 , 967-974 (2007).

41. Diehl, S. etal. Inhibition of Th1 differentiation by IL-6 is mediated by SOCS1. Immunity 13, 805-815 (2000).

42. Serada, S. et al. IL-6 blockade inhibits the induction of myelin antigenspecific Th17 cells and Th1 cells in experimental autoimmune encephalomyelitis. Proc. Natl. Acad. Sci. USA 105, 9041-9046 (2008).

43. Thakker, P., Leach, M.W., Kuang, W., Benoit, S.E., Leonard, J.P. \& Marusic, S. IL-23 is critical in the induction but not in the effector phase of experimental autoimmune encephalomyelitis. J. Immunol. 178, 25892598 (2007).

44. Kaiga, T., Sato, M., Kaneda, H., Iwakura, Y., Takayama, T. \& Tahara, H. Systemic administration of IL-23 induces potent antitumor immunity primarily mediated through Th1-type response in association with the endogenously expressed IL-12. J. Immunol. 178, 7571-7580 (2007).

45. Prochazkova, J., Pokorna, K. \& Holan, V. IL-12 inhibits the TGF-betadependent $\mathrm{T}$ cell developmental programs and skews the TGF-beta- induced differentiation into a Th1-like direction. Immunobiology 217, 74-82 (2012).

46. Heiseke, A. F. et al. CCL17 promotes intestinal inflammation in mice and counteracts regulatory $\mathrm{T}$ cell-mediated protection from colitis. Gastroenterology 142, 335-345 (2012).

47. Atarashi, K. et al. Induction of colonic regulatory T cells by indigenous Clostridium species. Science 331, 337-341 (2011).

48. Round, J. L. \& Mazmanian, S.K. Inducible Foxp3 + regulatory T-cell development by a commensal bacterium of the intestinal microbiota. Proc. Natl. Acad. Sci. USA 107, 122042010).

49. Meylan, F. et al. The TNF-family cytokine TL1A drives IL-13-dependent small intestinal inflammation. Mucosal Immunol 4, 172-185 (2011).

50. Sun, B. et al. Genetic susceptibility to experimental autoimmune uveitis involves more than a predisposition to generate a T helper-1-like or a T helper-2-like response. J. Immunol. 159, 1004-1011 (1997).

51. Slingsby, J.H., Hogarth, M.B., Simpson, E., Walport, M.J. \& Morley, B.J. New microsatellite polymorphisms identified between C57BL/6, C57BL/10, and C57BL/KsJ inbred mouse strains. Immunogenetics 43, 72-75 (1996).

52. Rioux, J.D. et al. Genetic variation in the $5 \mathrm{q} 31$ cytokine gene cluster confers susceptibility to Crohn disease. Nat. Genet. 29, 223-228 (2001).

53. Brescianini, S., Trinh, T., Stoll, M., Schreiber, S., Rioux, J.D. \& Daly, M.J. IBD5 is associated with an extensive complicated Crohn's disease feature: implications from genotype-phenotype analysis. Gut 56, 149-150 (2007). 